\title{
Periosteal chondroma in the scapular spine: a case
} report

\begin{abstract}
Introduction: The majority of scapular tumors have a cartilaginous origin, being the osteochondroma the most frequent. In this article we will review the main characteristics of the osteochondroma and another rare tumor, the periosteal chondroma, a benign bone tumor that arises from the deep layers of the periosteum from which there are not much cases published.

Presentation of Case: We present an unusual case of a periosteal chondroma located in the scapular spine in a 25 -year-old women. The first impression given by diagnostic imaging studies was a parosteal growth tumor, however given the rarity of these tumors; it was initially diagnosed as osteochondroma. Being a symptomatic tumor, complete excision with safety margins was performed. After histological examination of the tissue, it was finally diagnosed as periosteal chondroma.
\end{abstract}

Results: There were no postoperative complications. After 6 months follow up, the clinical results are positive, being the patient free of disease with complete recovery and a normal function of the scapulohumeral joint with full range of motion. To date there is absence of tumor recurrence.

Discussion: The definitive diagnosis of chondral type tumors is difficult to establish, requiring the combination of clinical, radiological imaging and histopathology of the lesion. The recognition of these features enables a correct diagnosis to be made.

Conclusion: Periosteal chondromas are very rare tumors from which there are very few cases reported in the literature. It is important to know well its characteristics and be careful when analysing these lesions.
Volume 9 Issue I - 2017

\author{
García Moreno J,' Montaner Alonso D,' \\ Alastrué Giner B,' Pose Lapausa P2 \\ 'Orthopaedic Surgery and Traumatology Department, Hospital \\ Universitario Doctor Peset, Spain \\ ${ }^{2}$ Pathology Department, Hospital Universitario Doctor Peset, \\ Spain
}

Correspondence: Garcia Moreno J, Orthopaedic and

Traumatology Department, Hospital Universitario Dr. Peset, Av. Gaspar Aguilar 90, 46017 Valencia, Spain;

Email pepo.garcia.med@gmail.com

Received: August 16, 2017| Published: September 19, 2017

\section{Introduction}

Primary tumors of scapula are rare. The majority of them have a cartilaginous origin, being the most frequent the osteochondroma, followed by the chondrosarcoma. In this article we will review the main features of the osteochondroma and another rare tumor, the periosteal chondroma, from which there are very few cases reported in the literature. After reviewing the main features of both tumors, we describe an unusual case of a periosteal chondroma located in the scapular spine in a 25 -year-old woman.

\section{Osteochondroma}

The osteochondroma is the most common benign bone lesion, representing approximately $45 \%$ of all benign bone tumors, although the true incidence is unknown because most of the lesions are asymptomatic and never identified. ${ }^{1}$ Osteochondroma may be solitary $(90 \%)$ or multiple forming part of the Multiple Hereditary Exostoses Syndrome (HME) in about $10 \%$ of cases. ${ }^{2}$ They arise from the outer edge of the growth plate and grow down the metaphyseal side where they tend to protuberate away from the adjacent joint.

The most common sites of occurrence are the metaphysis of large bones of the lower limb, especially in the distal end of the femur and proximal tibia. In the upper limb, proximal humerus is usually a common location. In this site, the osteochondroma is usually sessilebased instead of having the typical pedunculated stem and is frequently misdiagnosed for that reason. Other less frequent locations are the hands and feet, scapula, pelvis and ribs. It is exceptional at epiphyseal bone level and in bones following a membranous ossification. Although it is not frequent their appearance in the scapula, they represent the most common tumor in it. Considering the statistics, one third of the tumors located in the scapula are osteochondromas, however, only $4.6 \%$ of osteochondromas are located in this bone.

It is more common in males. It often rises during the early years of childhood, but as they are asymptomatic lesions, they are usually diagnosed accidentally between the age of 6 and 20 years old. The most common clinical evolution is the development of a painless mass of slow growth. As it is originated from the growth plate, it continues developing during the growing years of the patient and then stops at maturity.

The pathognomonic radiologic feature of this tumor is a pedunculated exophytic lesion with well-defined cortical edges and medullary continuity with the adjacent bone from which it arises (Figure 1). ${ }^{3} \mathrm{CT}$ and MRI allow excellent visualization of the corticomedullar continuity of the lesion, and are very useful for preoperative planning in areas of complex anatomy. Furthermore, MRI is considered as the best method for displaying the structures surrounding the lesion, detecting complications (e.g. Pseudoaneurysms) and for measuring the thickness of the cartilaginous layer, important fact when differentiation with chondrosarcoma is required. On MRI, the cartilaginous part shows a hyperintense signal on $\mathrm{T} 2$ and peripheral enhancement when contrast (gadolinium) is used. ${ }^{3}$

In the differential diagnosis we must take into consideration, although rare, the periosteal chondroma among others. The main radiologic feature of this tumor, that would be described later, isthat it has a rim of lamellar bone that separates the tumor from the medullary cavity.

The most serious complication is its malignant transformation to chondrosarcoma. It is usually exceptional, occurring in less than 
$1 \%$ of solitary lesions. This malignant conversion is more frequent in MHE syndrome (1-20\%). ${ }^{4}$ Most secondary chondrosarcomas present histological features of low-grade malignancy. They have a good prognosis and surgical treatment without adjuvant chemotherapy or irradiation is the treatment of choice. ${ }^{5}$ The findings that suggest malignancy are pain symptoms, cartilage thickness greater than 2 $\mathrm{cm}$ in an adult patient, growth of a previously stable lesion, irregular margins and erosion or destruction of adjacent bone.

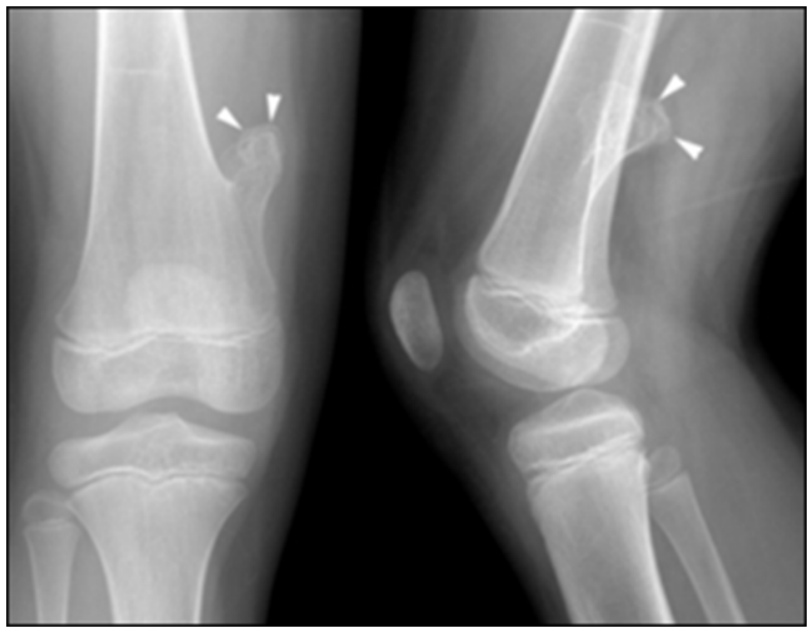

Figure I Osteochondroma in a 7 years old child distal femur. Front and lateral radiographs showing the typical findings of an osteochondroma with cortical and medullary continuity. The cortex surrounding the lesion is smooth and continuous.

The therapeutic management of the osteochondroma depends on the clinic. The presence of a solitary asymptomatic lesion is not an indication for surgical excision. If the exostosis causes symptoms, deformity of limbs, soft tissue lesions, then it must be excised. Surgical excision is also mandatory if an enlargement of the tumor is noticed or if thickness of the cartilaginous cap exceeds more than 2-3 cm, to avoid possible malignant transformation. The complete surgical resection of the tumor is the treatment of choice. Recurrence is not common to happen, but it may be seen when the removal is incomplete. ${ }^{5}$

\section{Periosteal chondroma}

The periosteal chondroma (or, yuxtacortical chondroma) is an unusual benign cartilaginous tumor. They represent $0,5 \%$ of all chondromas. It arises from the deep layers of the periosteum often at the metaphyseal ends of long bones. Unlike osteochondromas, which also develop on the surface of bones, periosteal chondromas are not related to the metaphyseal plates and most likely develop through subperiosteal cartilage formation. ${ }^{6}$ The most common site of appearance is the proximal humerus, femur, tibia and less often the bones of the hand and feet. ${ }^{7}$ Its location at the scapula is rare. In the literature reviewed there are only two reports of periosteal chondroma arising from the scapula. ${ }^{8,9}$

They are usually diagnosed between the 2 nd and 3rd decades of life, with a slight predominance in men. However, there are some cases published affecting children. ${ }^{8}$ The clinical presentation is usually as a painless mass on the bone surface, discovered incidentally either in clinical or radiographic examination for other reasons. The presence of pain is especially important when differential diagnosis with other cartilage lesions, as it may indicate malignant behaviour. Usually they are less than $3 \mathrm{~cm}$ size, although it may sometimes reach up to $5 \mathrm{~cm}$. Depending on their location they can generate compression on neuro- vascular structures causing referred symptoms such as in the case of the scapula, "winged scapula" by long thoracic nerve involvement. No malignant transformation, metastasis or multiple lesions have been reported. ${ }^{6}$ however, low-grade chondrosarcomas are always a major differential diagnosis in cases of periosteal chondroma.

On radiographic imaging, the periosteal mass indents the underlying cortex resulting in a scalloped depression, the inner border of which may show a rim of endosteal or cortical sclerosis. It rarely extends into the medullary cavity. Up to $50 \%$ of cases may have calcifications inside. Minor elevation of the bony cortex at the margins of the lesion is also a feature. ${ }^{10}$ In some cases, periosteal chondroma can generate a bone protuberance simulating osteochondroma (Figure 2).
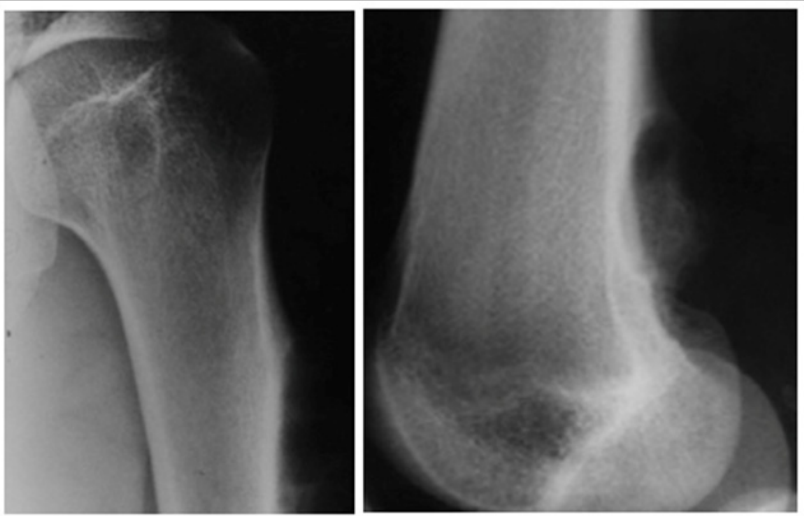

Figure 2a AP image: Periosteal chondroma in the humerus in a 19-year-old patient. In the picture we can see a lobed outline caused by cortical erosions.

Figure 2b Lateral image: Periosteal chondroma in the distal femur in a 17-year-old patient. In the image we can see lobular cortical erosions, a sclerotic bone reaction below the lesion and periosteal reaction in the back of the tibial metaphysis. ${ }^{18}$

In MR images, these tumors show intermediate signal on $\mathrm{T} 1$ sequences and high signal intensity on T2 images. To differentiatemalignant lesions, mainly chondrosarcoma, radiological criteria such as location, size, the presence of periosteal reaction and cortical response should be applied.

Histologically, lobes of hyaline cartilage surrounded by fibrous connective tissue or cortical bone form the periosteal chondroma. It is usually normocellular, but sometimes it can present increased cellularity and even moderate cytologic atypia (presence of binucleated cells with prominent nucleoli).

As in osteochondroma, the therapeutic management of periosteal chondroma depends on the clinic. If asymptomatic, regular monitoring is advisable with serial radiographs. If symptoms occur, the complete surgical resection of the tumor with free safety margins is the treatment of choice. ${ }^{6}$ Recurrence has been reported after conservative treatment (intralesional excision or curettage), however after complete excision recurrence is practically non-existent. ${ }^{8}$

\section{Methods and materials}

We present an unusual case of a periosteal chondroma located in the scapular spine in a 25 -year-old women. The patient was referred to the Orthopaedics and Traumatology service because she had a palpable mass in the right scapular region causing dorsal asymmetry. On physical examination, there was a palpable mass over the uppermedial aspect of the scapular spine, hard in consistency and causing mild pain to the patient. There was no restriction of the motion of the scapula. She reported that in the last two months it had increased in size accompanied with pain. 
An X-ray, CT scan and MRI were performed showing a welldefined lesion arising from the medial side of the right scapular spine (Figure 3). The initial diagnostic impression was of a tumor of chondral lineage, with findings that guided to the diagnosis of periosteal chondroma. However, given the rarity of these tumors, it was initially diagnosed as osteochondroma. After consulting the radiology department and due to the symptoms described by the patient, we proceeded to the removal of the lesion. We also performed a complete physical examination of the patient's limbs in order to discard other exostosis.

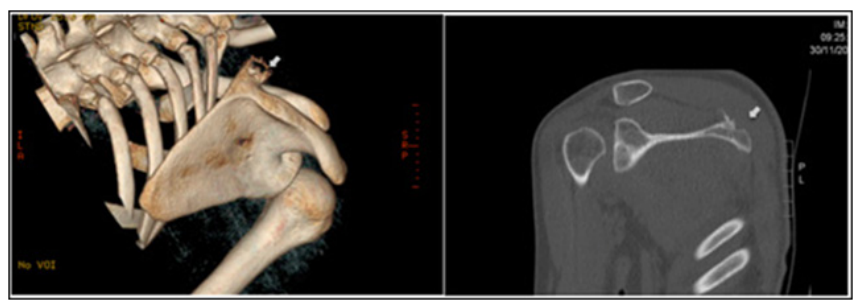

Figure 3 Images: a. 3D CT image. It is observed how the mass deforms the cortical border/contour generating a lobed surface with small erosions. b. CT image. Coronal oblique. In the image a thin rim of lamellar bone separates the tumor from the medullary cavity.

A direct scapular approach was made using a $5 \mathrm{~cm}$ incision (Figure 4). Macroscopically, the periosteal tumor consisted of a sessile oval cartilaginous exostosis, measuring $3 \times 2 \times 2 \mathrm{~cm}$. The tumor was well circumscribed, without muscular or subcutaneous tissue invasion. It was rejected from its base with free safety margins.
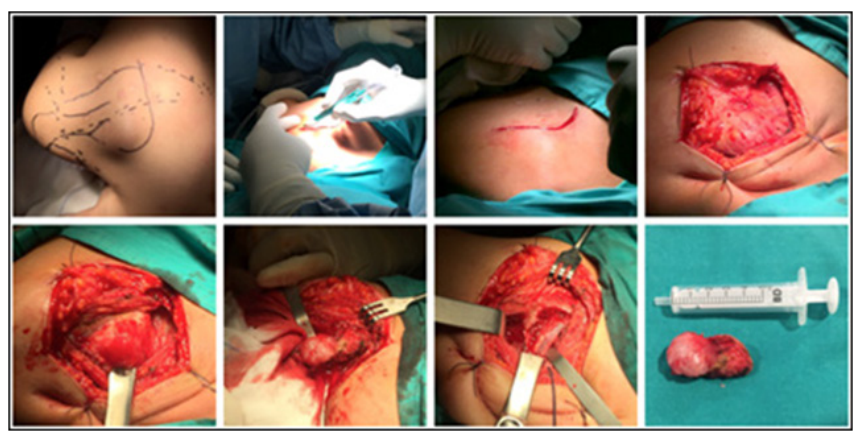

Figure 4 Surgical images of the tumor in the medial border of the scapula spine.

\section{Results}

The resected mass was sent for histological analysis. The microscopic examination of the samples showed mature hyaline cartilage arranged in a lobular pattern with little fibrous tissue between them (Figure 5). Chondrocytes showed no nuclear atypia or mitosis. The lesion was coated on its outer part by periosteum, and internally by trabecular bone. Bone marrow cells were not observed within trabecular bone tissue. The margins of the mass were delineated with no evidence of invasion of adjacent structures. Furthermore, the absence of cytologic atypia, the perfect definition of the lesion, the absence of breakage of cortical bone, and the clinical features made us discard a malignant tumor origin.

After 6 months of follow up after the surgery, the patient is asymptomatic, with complete recovery and presents a normal function of the scapulohumeral joint with full range of motion. The report of the MRI control practiced 6 months after the intervention details the absence of tumor. It should be noted that the monitoring period is still short, despite that the likelihood of recurrence of these tumors after resection is very low. The patient will follow annual clinical and imaging revisions over the next three years to confirm the absence of tumor recurrence.

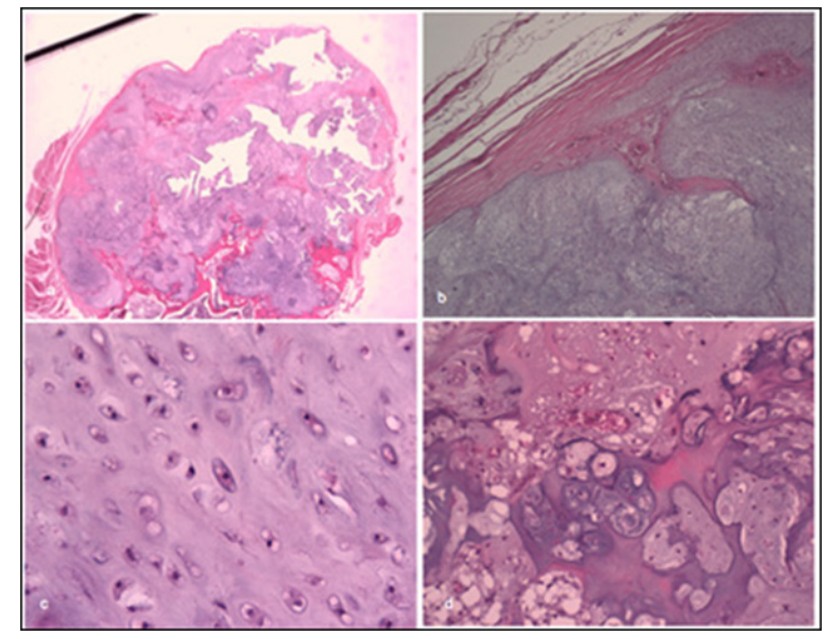

Figure 5 Images from the pathology study.

a. Well circumscribed lesion formed by hyaline cartilage lobes.

b. Periosteal coverage.

c. Absence of atypia in the chondrocytes.

d. Endochondral ossification focus

\section{Discussion}

Chondral type tumors are often difficult to differentiate as they share many clinical, pathological and radiological features. It is important to know well its characteristics in order to make an accurate diagnosis. In our study, initially there was a discussion with the pathology department about the definitive diagnosis of the tumor. The first impression given by radiologists was a periosteal dependent tumor, since it did not seem to invade bone marrow. However, the pathology department had more doubts because of the many similarities between chondroid tumors. Finally, after a thorough study of the case, the final pathological diagnosis was periosteal chondroma.

Differentiating whether it is an osteochondroma or a periosteal chondroma has its importance in the post-surgical prognosis. The treatment of choice for osteochondromas is complete surgical excision by the base. This should normally prevent tumor recurrence. If recurrence happens after complete excision, suspicion of malignancy should be raised. ${ }^{11}$ In contrast, the therapeutic management of periosteal chondroma is marginal excision (complete surgical resection of the tumor with free safety margins). If this is not made, the probability of tumor recurrence increases. ${ }^{12}$

In addition, it is important to make a correct differential diagnosis between periosteal chondromas and low-grade chondrosarcomas. Periosteal chondromas are predominantly normocellular, but hypercellularity and mild atypia may be present, without being considered to be signs of malignancy. ${ }^{13}$ Chondrosarcomas are larger in size (exceeding a size of 3-4 cm in diameter), usually occur in elder people, and they may have soft tissue extension. ${ }^{6}$ Also, both tumors may show scalloping and sclerosis of the cortex, but periosteal chondrosarcomas tend to permeate the underlying bone and periosteal chondromas do not. In our case, the imaging features of the tumor were characteristic of a periosteal chondroma but not of a periosteal chondrosarcoma. A correct differential diagnosis between these two tumors is necessary in order to avoid aggressive and inappropriate treatment. ${ }^{14-19}$ 


\section{Conclusion}

The definitive diagnosis of chondral type tumors is difficult to establish, requiring the combination of clinical, radiological imaging and histopathology of the lesion. The recognition of these features enables a correct diagnosis to be made. Given the low incidence of periosteal chondromas in the scapula and the few cases reported in the literature, it was decided to present this work.

All human studies have been approved by the appropriate ethics committee and have therefore been performed in accordance with ethical standards laid down in the 1964 Declaration of Helsinki and it's later amendments.

\section{Acknowledgments}

None.

\section{Conflicts of interest}

None.

\section{References}

1. Herrera-Perez M, Aciego De Mendoza M, De Bergua-Domingo JM et al. Osteochondromas around the ankle: Report of a case and literature review. Int J Sur Case Report. 2013;4(11):1025-1027.

2. Mondal S, Chowdhury A, Bandyopadhyay R et al. Pseudo winging and snapping of scapula due to sub scapular osteochondroma-a rare case report. IOSR Journal of Dental and Medical Sciences (IOSR-JDMS). 2014;13(1):37-40.

3. Marco Cañete P, Elena Fontoira M, Gutiérrez San Jose B et al Osteocondroma: diagnóstico radiológico, complicaciones y variantes. Revista chilena de radiología. 2013;19(2):73-81.

4. Carpintero P, Del Fresno JA, Carpintero R et al. Complicaciones de los osteocondromas. Revista española de cirugía osteoarticular. 2009;44:237.

5. Kitsoulis $\mathrm{P}$, Galani A, Stefanaki $\mathrm{K}$ et al. Osteochondromas: Review of the clinical, radiological and pathologic features. In vivo. 2008;22(5):633-646.

6. Al-Qudah AS, Hamdi M, Abu-Ali et al. Periosteal chondroma of the clavicle: Case report and review of the literature. International Journal of Surgery. 2009;7(2):140-141.
7. Bauer TW, Dorfman H.D, Latham JT Periosteal chondroma. A clinicopathologic study of 23 cases. Am J Surg Pathol. 1982;6(7):631-637.

8. Gunduz T, Fahrettin G, Mehmet T et al. Fperiosteal chondroma of scapula: A case report. Surgery Journal. 2006;1(1):29-31.

9. Rubenstein DJ, Harkavy L, Glantz L Case report 518: Periosteal chondroma of scapula. Skeletal Radiol. 1989;18:47-56.

10. Douis H, Saifuddin A The imaging of cartilaginous bone tumours. I. Benign lesions. Skeletal Radiol. 2012;41(10):1195-1212.

11. Sreenivas T, Kumar NR, Nataraj AR A retrospective analysis of osteochondroma of scapula following excision biopsy. Acta Orthop Belg. 2015;81(2):303-307.

12. Sirichai Luevitoonvechkij L, Arphornchayanon O, Leerapun $\mathrm{T}$ et al. Periosteal Chondroma of the Proximal Humerus: A Case Report and Review of the Literature. J Med Assoc Thai. 2006;89(11).

13. Yoshinori Imura, Atsuo Shigi, Hidetatsu Outani et al. A giant periosteal chondroma of the distal femur successfully reconstructed with synthetic bone grafts and a bioresorbable plate: a case report. World Journal of Surgical Oncology. 2014;12:354.

14. Dekker AP, Grimer RJ Transformation of solitary osteochondroma to dedifferentiated chondrosarcoma arising in the distal radius: a case report. Musculoskelet Surg. 2013;97(1):89-92.

15. López Martín N, Calvo Crespo E, Álvarez Galovich L Tumores de escápula de estirpe cartilaginosa. Rev Ortop Traumatol. 2002;3(1-2):259-262.

16. Iván Melo G, Virginia Martínez C. Tumores óseos condroides: Condromas versus condrosarcomas convencionales. Chilena de Radiología. 2005;11(4):170-178.

17. Ramos-Pascua LR, Sánchez-Herráez S, Alonso-Barrio JA, AlonsoLeón A Osteocondromas solitarios del extremo proximal del fémur. Indicación y resultados de la resección en bloque sin luxación de la cadera. Rev esp cir ortop traumatol. 2012;56(1):24-31.

18. Woertler K, Blasius S, Brinkschmidt C et al. Periosteal Chondroma: MR Characteristics. J Comput Assist Tomog. 2001;25(3):425-430.

19. Kahn S, Taljanovic MS, Speer DP et al. Kissing periosteal chondroma and osteochondroma. Skeletal Radiol. 2002;31:235-239. 